\title{
Magneto-resistance of $\mathrm{Nano}_{-} \mathrm{Fe}_{3} \mathrm{O}_{4} / \mathrm{Ag}$ Granular System
}

\author{
Y. Kimishima, W. Yamada, K. Kobayashi, M. Uehara, \\ T. Asaka ${ }^{*}, \mathrm{~K}$. Kimoto $^{*}$, and Y. Matsui ${ }^{*}$ \\ Department of Physics, Faculty of Engineering, Yokohama National University, Tokiwadai 79-5, Hodogaya-ku, Yokohama \\ 240-8501, Japan \\ *Advanced Materials Laboratory (AML), National Institute for Materials Science (NIMS), Namiki 1-1, Tsukuba 305-0044, Japan
}

Four kinds of $\mathrm{Fe}_{3} \mathrm{O}_{4} / \mathrm{Ag}$ granular systems were prepared from sintered mixtures of $\mathrm{Fe}_{3} \mathrm{O}_{4}$ and $\mathrm{Ag}$ or $\mathrm{Ag}_{2} \mathrm{O}$. Magneto-resistances (MRs) were measured at room temperature for samples with $\mathrm{Ag}$ volume fraction $x$ between 0 and 0.4 . Samples including relatively large $\mathrm{Fe}_{3} \mathrm{O}_{4}$ grains showed $-1 \%$ to $-1.4 \%$ room temperature MR ratios $(M R R)$ at $1 \mathrm{~T}$. On the other hand, samples including $\mathrm{Fe}_{3} \mathrm{O}_{4}$ nano-particles showed large negative room temperature $M R R$ of about $-4 \%$ to $-5 \%$ at $1 \mathrm{~T}$ near the percolation threshold of $x_{\mathrm{c}} \sim 0.2$. It was suggested that $\mathrm{Fe}_{3} \mathrm{O}_{4} / \mathrm{Ag} / \mathrm{Fe}_{3} \mathrm{O}_{4}$ paths were effective for the large $|M R R|$ by the elastic conduction of spin-polarized electrons between $\mathrm{Fe}_{3} \mathrm{O}_{4}$ nano-particles. Possibility of spin accumulation in small $\mathrm{Ag}$ particles was also shown for this system.

Key words: half-metallic oxide, magnetically ordered materials, nano-granular system, magneto-resistance

\section{Introduction}

Half metallic magnetite $\left(\mathrm{Fe}_{3} \mathrm{O}_{4}\right)$ junctions with $-100 \%$ spin polarization of conduction $d$ electrons have been expected to realize the new oxide magnetic storage devices such as magnetic random access memory (MRAM) by large negative magneto-resistance (MR). In the thin films of $\mathrm{Fe}_{3} \mathrm{O}_{4}$, negative room temperature MR-ratios $(M R R)$ of about $-1 \%$ at $1 \mathrm{~T}$ have been reported for polycrystalline and single crystalline samples [1-8]. These $M R R$-results were interpreted as one of the intrinsic effects by the electron hopping between $\mathrm{Fe}^{2+}$ and $\mathrm{Fe}^{3+}$ ions. The large MR effect can be anticipated by the tunneling MR (TMR) through the thin insulating barriers between $\mathrm{Fe}_{3} \mathrm{O}_{4}$-grains. Relatively high $|M R R|$-results about $5 \%$ at $1 \mathrm{~T}$ have been reported for room temperature (RT) TMR in $\mathrm{Fe}_{3} \mathrm{O}_{4}$ films with oxide barriers such as $\mathrm{MgO}$ [9], $\gamma-\mathrm{Fe}_{2} \mathrm{O}_{3}$ [10-12] and $\mathrm{ZnFe}_{2} \mathrm{O}_{4}$ [13]. The $M R R$ was defined here as $[\rho(H)-\rho \max ]$ / $\rho_{\max }$, where $\rho$ was the resistivity and $\rho_{\max }$ was the maximum one in low magnetic field region. In the bulk granular system, the $\mathrm{Zn}_{0 \cdot 41} \mathrm{Fe}_{2.59} \mathrm{O}_{4}$ with $\alpha-\mathrm{Fe}_{2} \mathrm{O}_{3}$ grain boundaries [14] showed a largely negative RT-MRR of $-61 \%$ at $1 \mathrm{~T}$, though it disappeared above $320 \mathrm{~K}$. For nano-contacted $\mathrm{Fe}_{3} \mathrm{O}_{4}$ particles [15], the RT-MRR of $-75 \%$ at $8 \mathrm{mT}$ was reported, but the nano-contacting parts were unstable against a small external turbulence.
In the present work, RT-MR effects in $\mathrm{Fe}_{3} \mathrm{O}_{4} / \mathrm{Ag}$ nano-granular systems were investigated, expecting the large RT-MRR with well reproducibility by physical and chemical stabilization of the conduction paths by the metallic Ag for the polarized conduction electrons among $\mathrm{Fe}_{3} \mathrm{O}_{4}$ nano-grains.

\section{Sample preparation}

Four kinds of samples with $\mathrm{Fe}_{3} \mathrm{O}_{4}$ nano-grains were prepared by the following procedures. First, the precursor of $\mathrm{Fe}_{3} \mathrm{O}_{4}$ nano-particles were precipitated by mixing aqueous solution of $\mathrm{FeCl}_{2} \cdot 4 \mathrm{H}_{2} \mathrm{O}, 2 \mathrm{FeCl}_{3} \cdot 6 \mathrm{H}_{2} \mathrm{O}$ and aqueous ammonia. Then the obtained $\mathrm{Fe}_{3} \mathrm{O}_{4}$ nano-particles were mixed with commercial $\mathrm{Ag}$ (samples I) or $\mathrm{Ag}_{2} \mathrm{O}$ (samples II) powders. They were sintered at $473 \mathrm{~K}$ in the Ar atmosphere with $1.5 \% \mathrm{H}_{2}$ gas. The prepared samples had the Ag volume fraction of $x=V_{\mathrm{Ag}}$ $/\left(V_{\mathrm{Fe} 3 \mathrm{O} 4}+V_{\mathrm{Ag}}\right)$ between 0 and 0.35 . On the other hand, the samples III were directly precipitated by mixing the aqueous solution of $\mathrm{FeCl}_{2} \cdot 4 \mathrm{H}_{2} \mathrm{O}, 2 \mathrm{FeCl}_{3} \cdot 6 \mathrm{H}_{2} \mathrm{O}$ and the aqueous ammonium solution of $\mathrm{Ag}_{2} \mathrm{O}$, but solvable $\mathrm{Ag}$ volume fraction $x$ was limited to 0.13 . At $x$ larger than 0.13 , the $\mathrm{Ag}_{2} \mathrm{O}$ powder particles partially deposited in the mixed solution. Therefore, for samples III, only the precipitates in $0<x<0.13$ were sintered under the same condition as former samples I and II. The samples $\underline{\mathrm{C}}$ were obtained from the sintered powder mixtures of commercial $\mathrm{Fe}_{3} \mathrm{O}_{4}$ and $\mathrm{Ag}$ at $773 \mathrm{~K}$ in the atmosphere of $\mathrm{H}_{2}: \mathrm{Ar}=0.02: 0.98$.

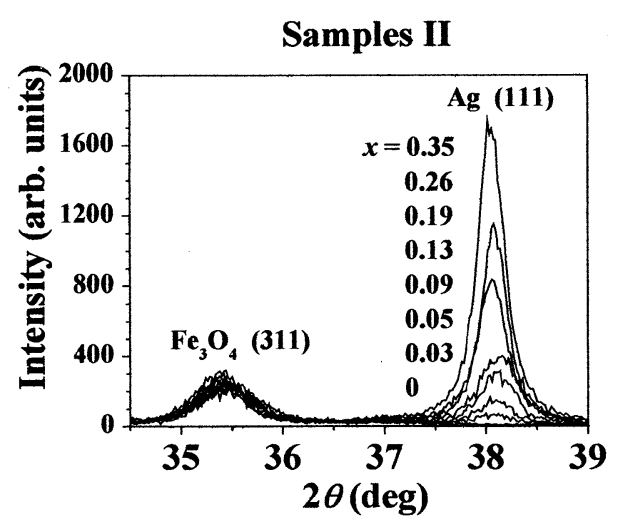

Fig. 1 XRD main peaks of (311) for $\mathrm{Fe}_{3} \mathrm{O}_{4}$ and (111) for $\mathrm{Ag}$ in samples II for values of $x$ between 0 and 0.35 .

The $\mathrm{x}$-ray diffraction (XRD) patterns of samples II 
were given in Fig. 1 for the (311) main peak of $\mathrm{Fe}_{3} \mathrm{O}_{4}$ and (111) one of $\mathrm{Ag}$. From the half widths of diffraction peaks, the mean particle diameters $d$ were estimated from Scherrer's formula for $\mathrm{Fe}_{3} \mathrm{O}_{4}\left(d_{\mathrm{Fe} 3 \mathrm{O} 4}\right)$ and $\mathrm{Ag}\left(d_{\mathrm{Ag}}\right)$. The $x$ dependences of $d_{\mathrm{Fe} 3 \mathrm{O} 4}$ and $d_{\mathrm{Ag}}$ were shown in Fig. 2 .

In samples $\mathrm{C}, d_{\mathrm{Fe} 3 \mathrm{O} 4}$ and $d_{\mathrm{Ag}}$ were nearly constant at about $30 \mathrm{~nm}$, which was the same order to the precursor of commercial powders, though the agglomeration of the grains can not be excluded in them. The $d_{\mathrm{Fe} 304}$-values of samples I were $15 \sim 20 \mathrm{~nm}$ in $x<0.1$ and about $30 \mathrm{~nm}$ in $x>0.1$. The $d_{\mathrm{Ag}}$-values were $20 \sim 25 \mathrm{~nm}$ in $x<0.1$ and 30 $\sim 35 \mathrm{~nm}$ in $x>0.1$.

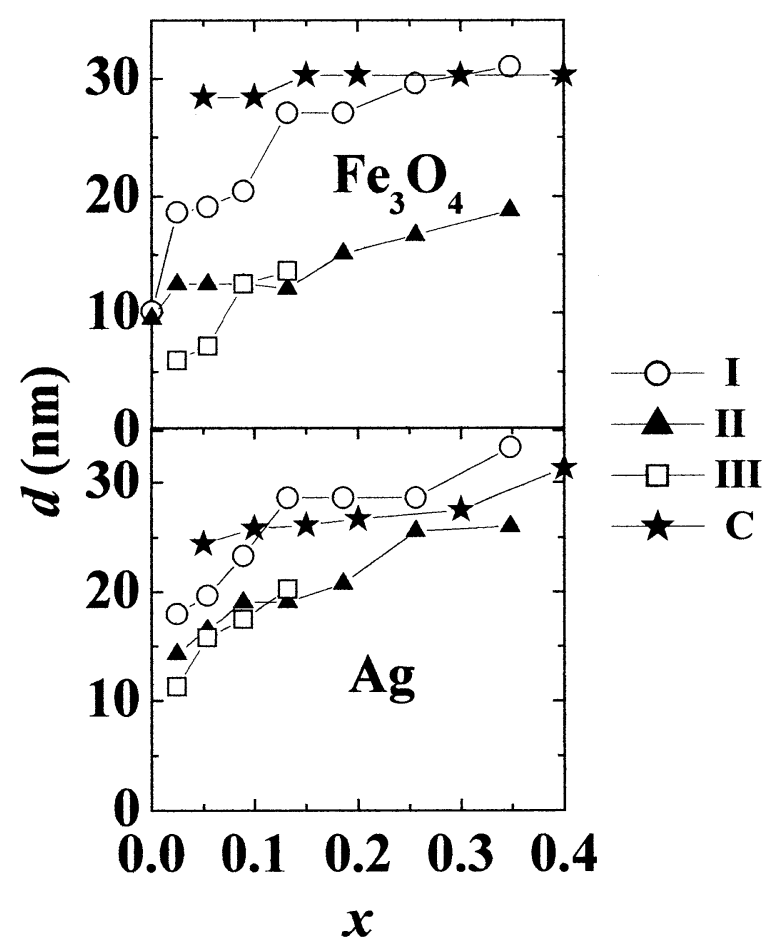

Fig. $2 x$-dependences of the particle diameters of $d_{\mathrm{Fe} 3 \mathrm{O} 4}$ and $d_{\mathrm{Ag}}$, determined from XRD results.

The $d_{\mathrm{Fe} 3 \mathrm{O} 4}$-values of samples II were $10 \sim 15 \mathrm{~nm}$, and the $d_{\mathrm{Ag}}$-values were $15 \sim 25 \mathrm{~nm}$ in $x<0.4$. These results mean that the samples II formed a good nano-particle system of $\mathrm{Fe}_{3} \mathrm{O}_{4}$ and $\mathrm{Ag}$ in whole $x$-region between 0 and 0.4 , though the samples III included smaller $\mathrm{Fe}_{3} \mathrm{O}_{4}$ particles in $0<x<0.13$. Therefore we mainly paid attention to the MR-behaviors of samples II as one of the typical nano- $\mathrm{Fe}_{3} \mathrm{O}_{4}$ and $\mathrm{Ag}$ granular systems.

The transmission electron microscopy (TEM) images of sample II at $x=0.05$ and 0.19 were shown in Figs. 3 (a) and (b), where we used a crushing method to prepare the electron microscopy specimens. Some samples were ground under $\mathrm{CCl}_{4}$, then, dispersed on carbon coated micro-grids. Specimens were examined with Hitachi HF-3000S field-emission analytical TEM operating at $300 \mathrm{kV}$.

Since the very dense Debye rings were obtained, it was very difficult to choose a ring of $\mathrm{Ag}$ - or $\mathrm{Fe}_{3} \mathrm{O}_{1}$-phase by an objective aperture in dark-filed imaging. TEM contrast might be affected also by crystal orientation and thickness. Therefore we judged that it was difficult to obtain a good image-formation by dark field, and qualitative analysis of the grain was performed by energy dispersive $\mathrm{x}$-ray spectroscopy (EDX). The EDX spectrum showed that the most darkened parts corresponded to Ag-particles, and the other to $\mathrm{Fe}_{3} \mathrm{O}_{4^{-}}$ particles. As shown in Fig. 3(a), the Ag-particles of $d \sim 20 \mathrm{~nm}$ are isolated in the connected $\mathrm{Fe}_{3} \mathrm{O}_{4}$-particles of $d=10 \sim 20 \mathrm{~nm}$ at $x=0.05$. At $x=0.19$, larger or agglomerated $\mathrm{Ag}$-particles began to appear, as shown in Fig. 3(b). These results were not contradictory to the above XRD results.

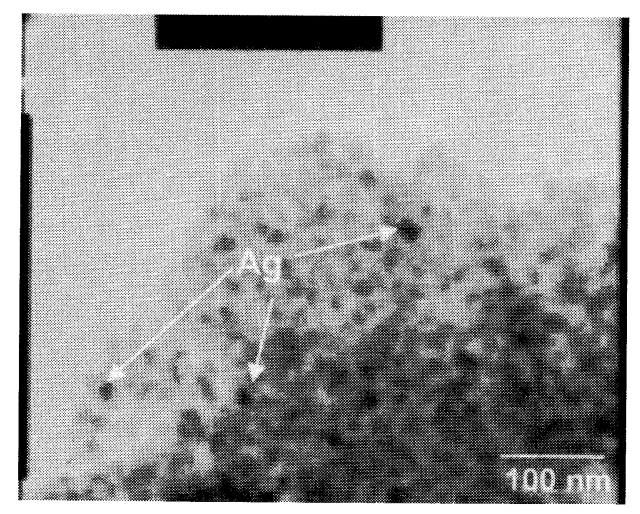

(a)

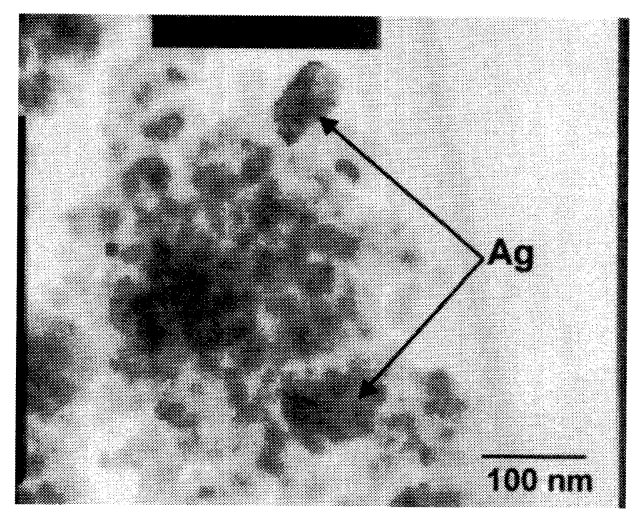

(b)

Fig. 3 TEM images of samples II for $x=0.05$ (a) and 0.19 (b).

\section{Results and discussion}

MR measurements were done by usual 4-terminals method in DC-field between $-1 \mathrm{~T}$ and $1 \mathrm{~T}$. To avoid the nonlinear effect between voltage $V$ and current $I$, resistance $R$ was measured at constant current $I$ of $1 \mathrm{~mA}$. Room temperature $M R R$-curves of samples II are partly shown in Fig. 4. They show slight hysteresis due to the small coercive force of $H_{\mathrm{c}}$. The $M R R$ absolute values 


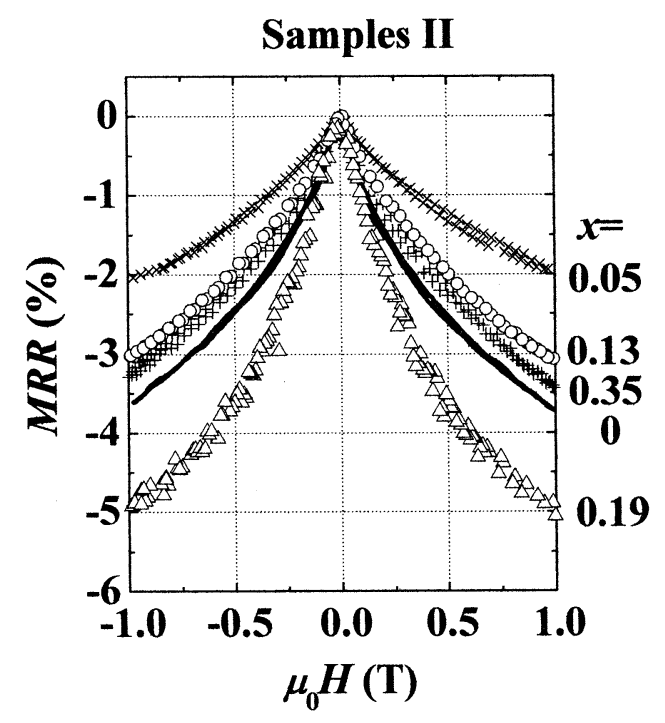

Fig. 4 Field dependences of the room-temperature MR ratios $(M R R)$ of samples II.

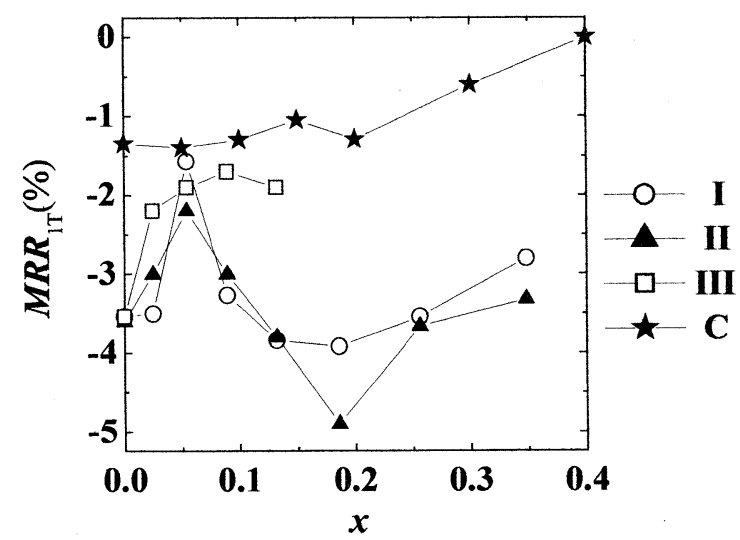

Fig. $5 x$-dependences of the MR ratios $(M R R)$ at $300 \mathrm{~K}$ and $1 \mathrm{~T}$ for all of the samples.

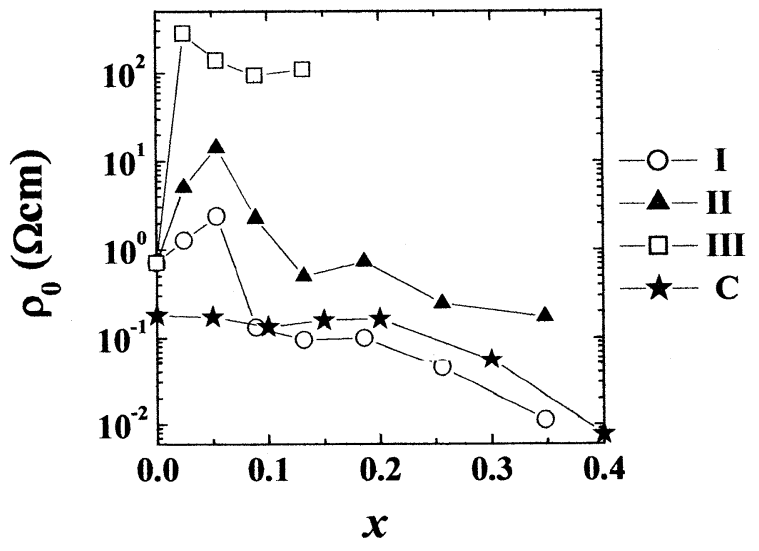

Fig. $6 x$-dependences of the 0 -field resistivity $\rho_{0}$ at 300 $\mathrm{K}$ for all of the samples. sharply increase in low field region and show no saturation at $\pm 1 \mathrm{~T}$, which correspond to the magnetization curves up to $1 \mathrm{~T}$ by SQUID magnetometer.

In Fig.5, MRR-values at $300 \mathrm{~K}$ and $1 \mathrm{~T}$ were plotted for all of the samples. It should be noted that the $|M R R|$ of samples I-III were commonly larger than the highest $|M R R|$-value of $1.4 \%$ in samples C. The $|M R R|$ of samples II reaches maximum value of $5.0 \%$ at $x=0.19$. For the samples I, largest $|M R R|$ of $3.9 \%$ was also observed at $x=0.19$. Both of maximum $|M R R|$-values are larger than the $|M R R|$ of $3.5 \%$ in the nano- $\mathrm{Fe}_{3} \mathrm{O}_{4}$ sample of $x=0$. These results may show the physical and chemical stabilization of intermediate conduction paths between $\mathrm{Fe}_{3} \mathrm{O}_{4}$ nano-particles.

The $\rho_{0}$ of room temperature resistivity at 0 field were shown in Fig. 6 for all of the samples. $\rho_{0}$ is nearly equal to the maximum resistivity for each sample because of the very small hysteresis in the $\rho-H$ curves. For samples II, $|M R R|$ and $\rho_{0}$ decreases and increases with increasing $x$ in $x<0.05$, and becomes minimum and maximum at $x=0.05$, respectively. Above $x=0.05$, $|M R R|$ increases and $\rho_{0}$ decreases with increasing of $x$, indicating visible peak at $x=0.19$. Above $x=0.19$, $|M R R|$ and $\rho_{0}$ decrease monotonously according to Ag-content. Samples I showed nearly the same behaviors with samples II. As for the samples III in $0<x<0.13$, minimum $|M R R|$ and maximum $\rho_{0}$ appeared at $x=0.08$ and $x=0.02$, respectively.

In the samples $\mathrm{C}, \rho_{0}$ was nearly constant in $x<0.2$, and rapidly decreases in $x>0.2$. The $|M R R|$ decreases with increasing $x$ below 0.2 . At $x \sim 0.2,|M R R|$ had an weak peak value of $1.3 \%$, when $\rho_{0}$ also showed a broad peak. In $x>0.2$, both of $|M R R|$ and $\rho_{0}$ began to decrease with increasing $x$. The weak peaks of $|M R R|$ near $x=0.2$ are also found for samples I and II.

Since the linear relation between voltage $V$ and current $I$ was confirmed in the resistivity measurement for $x>0.2$, the above experimental results around $x=$ 0.2 can be interpreted as the percolation behavior of $\mathrm{Ag}$ conducting paths with the percolation threshold $x_{\mathrm{c}}$ of about 0.2 . Similar results of peak in $|M R R|$ just below $x_{\mathrm{c}}$ were reported for the $\gamma-\mathrm{Fe}_{2} \mathrm{O}_{3} / \mathrm{Ag}$ granular nanocomposites [16]. Ordinary, the percolation problems were considered for the system including two kinds of conductive spheres with same diameter. Therefore it is not easy to apply the numerical results of percolation theory $[17,18]$ to the present system with different diameters of $d_{\mathrm{Fe} 3 \mathrm{O} 4}$ and $d_{\mathrm{Ag}}$. However the $x_{\mathrm{c}}$-value of 0.2 might reflect the theoretical percolation threshold of 0.198 obtained from the site model calculation for the closed packed fcc lattice [19].

Here we discuss the $|M R R|-$ and $\rho 0$-behaviors of samples I, II and III at $x$ around 0.05 , where the $|M R R|$ and $\rho_{0}$ become minimum and maximum, respectively. One of the possibility to explain the above results is the spin injection [20] into the $\mathrm{Ag}$ nano-particles. In a low field region, the magnetic moments in $\mathrm{Fe}_{3} \mathrm{O}_{4}$ particles are randomly oriented and spin injection to $\mathrm{Ag}$ particles dose 
not occur. However, in a high field, magnetic moments are aligned along the external field and the spin polarized electrons are injected into $\mathrm{Ag}$ nano-particles. If $d_{\mathrm{Ag}}$ is less than the spin diffusion length $d_{s}$, injected electron spins are accumulated in the $\mathrm{Ag}$ conducting paths. These nonequilibrium spins impede the spin current into $\mathrm{Ag}$ particles. Then resistivity increases by magnetic field, and the positive magneto-resistance effect appears. Actually, such an effect has been observed in $\mathrm{Fe}_{3} \mathrm{O}_{4}-\mathrm{Ag}$ composite films [21] when $d_{\mathrm{Ag}}$ is nearly equal to $d_{\mathrm{s}}$. If $d_{\mathrm{Ag}}>d_{\mathrm{s}}$, the orientation of injected spins are relaxed in the middle of the $\mathrm{Ag}$ path. When $d_{\mathrm{Ag}}<d_{\mathrm{s}}$, accumulated non-equilibrium magnetization in $\mathrm{Ag}$ particles would be fluctuated and diminished by thermal energy. Therefore, if the condition of $d_{\mathrm{Ag}} \sim d_{\mathrm{s}}$ is satisfied at $x \sim 0.05$, the absolute value of "negative" $M R R$ may be partially reduced by the positive $M R R$ by spin accumulation. The increasing of $\rho_{0}$ in 0 -field might be also due to the spin injection from the $\mathrm{Fe}_{3} \mathrm{O}_{4}$ particles in the remanent magnetic state.

No anomalous behaviors of $\rho_{0}$ and $|M R R|$ of samples C near $x=0.05$ can be explained by larger $d_{\mathrm{Fe} 304}$ than $d_{\mathrm{Ag}}$ which maintains directly conducting paths of $\mathrm{Fe}_{3} \mathrm{O}_{4} /$ $\mathrm{Fe}_{3} \mathrm{O}_{4}$. Even if the $\mathrm{Ag}$ content increases up to about $x=0.2$, small Ag particles may be incapable of connecting large $\mathrm{Fe}_{3} \mathrm{O}_{4}$ particles due to the large interstices. On the other hand, in samples I-III, the relation of $d_{\mathrm{Fe} 3 \mathrm{O} 4}<d_{\mathrm{Ag}}$ holds below $x=0.4$, except for samples I above $x=0.1$. Then the direct connection between $\mathrm{Fe}_{3} \mathrm{O}_{4^{-}}$and Ag-particles may be dominant due to the filling of interstices by large or agglomerated $\mathrm{Ag}$ particles as shown in Fig.3. Now the theoretical investigation of the site percolation problem may be important for the mixed system with different diameters of conductive particles to explain the MR-and $\rho_{0}$-behaviors in detail.

\section{Conclusion}

Room temperature magneto-resistances were measured and discussed for the four kinds of $\mathrm{Fe}_{3} \mathrm{O}_{4} / \mathrm{Ag}$ granular systems. Most of the systems commonly showed weak peaks of magneto-resistance ratio $|M R R|$ and 0 -field resistivity $\rho_{0}$ near the percolation threshold $x_{\mathrm{c}}$ of about 0.2 . The maximum $|M R R|$ of about $5 \%$, which is fairly high value for the granular $\mathrm{MR}$ of $\mathrm{Fe}_{3} \mathrm{O}_{4}$, was observed for nano- $\mathrm{Fe}_{3} \mathrm{O}_{4} / \mathrm{Ag}$ system prepared by sintering the mixture of $\mathrm{Fc}_{3} \mathrm{O}_{4}$ and $\mathrm{Ag}_{2} \mathrm{O}$ (samples II). Mcanwhilc thc possibilities of spin injection from $\mathrm{Fe}_{3} \mathrm{O}_{4}$ nano-particles and spin accumulation in $\mathrm{Ag}$ particles were suggested for the samples including $\mathrm{Fe}_{3} \mathrm{O}_{4}$ nano-particles (samples I, II and III) at $x$ around 0.05 .

It was also revealed that the site percolation problem for the mixed system, including two kinds of conductive particles with different diameters, is important to explain the $M R R$ and $\rho_{0}$ behaviors in the present granular systems.
In the $\mathrm{Fe}_{3} \mathrm{O}_{4} / \mathrm{Ag}$ nano-particle system, the $\mathrm{MR}$ behavior near Verwey transition temperature $T_{\mathrm{v}} \sim 120 \mathrm{~K}$ is another interesting problem. The $|M R R|$ experiments near $T_{\mathrm{v}}$ are now in progress for the present system and shall be reported elsewhere.

Acknowledgment The present work was financially supported by Takahashi Industrial and Economic Research Foundation. The TEM research was also supported by Nano- technology Support Project from the Ministry of Education, Science, Sports and Culture, Japan.

\section{References}

1) G.Q. Gong, A. Guputa, G. Xiao, W. Qian and V.P. Dravid, Phys. Rev. B, 56, 5096 (1997).

2) S.B. Ogale, K. Ghosh, R.P. Sharma, R.L. Greene, R. Ramesh and T. Venkatesan, Phys. Rev. B, 57, 7823 (1998).

3) J. M. D. Coey, A. E. Berkowitz, L. I. Balcells, F. F. Putris and F. T. Parker, Appl. Phys. Lett., 72, 734 (1998).

4) J. Tang, K. -Y. Wang and W. Zhou, J. Appl. Phys., 89, 7690 (2001).

5) P. Poddar, T. Fried and G. Markovich, Phys. Rev. B, 65, 172405 (2002).

6) M. Ziese, R. Hohne, H. C. Semmelhack, H. Reckentin, N. H. Hong and P. Esquinazi, Eur. Phys. J. B, 28, 415 (2002).

7) D.L. Peng, T. Asai, N. Nozawa, T. Hirata and K. Sumiyama, Appl. Phys. Lett., 81, 4598 (2002).

8) T. Taniyama, Y. Kitamoto and Y. Yamazaki, J. Appl. Phys., 89, 7693 (2001).

9) X. W. Li, A. Gupta, G. Xiao, W. Oian and V. P. Dravid, Appl. Phys. Lett., 73, 3282 (1998).

10) K. Nishimura, Y. Kohara, Y. Kitamoto and M. Abe, J. Appl. Phys., 87, 7127 (2000).

11) Y. Kitamoto, Y. Nakayama and M. Abe, J. Appl. Phys., 87, 7130 (2000).

12) M. Uotani, T. Taniyama and Y. Yamazaki, J. Appl. Phys., 87, 5585 (2000).

13) C. T. Lie, P. C. Kuo, V. -C. Hsu, I. J. Chang and J. W. Chen, J. Magn. Magn. Mat., 239, 160 (2002).

14) P. Cheng, D. Y. Xing, Y. W. Du, J. M. Zhu and D. Feng, Phys. Rev. Lett., 87, 107202 (2001).

15) J. I. Versluijs, M. A. Bari and J. M. D. Coey, Phys. Rev. Lett., 87, 026601 (2001).

16) J. Tang, L. Feng and J. A. Wieman, Appl. Phys. Lett., 74, 2522 (1999).

17) V. K. Shante, S. Kirkpatrick, Adv. Phys., 20, 325 (1971).

18) J. P. Straley, Phys. Rev. B, 15, 5733 (1977).

19) C. Domb and N. W. Dalton, Proc. Phys. Soc., 89, 859 (1966).

20) M. Johnson, R. H. Silsbee, Phys. Rev. Lett., 55, 1790 (1988).

21) J-H Hsu, S-Y Chen, C-R Chang, J. Magn. Magn. Mat., 242-245, 479 (2002).

Received September 30, 2004 ; Accepted January 14, 2005 